\title{
The Effect of Shadow 8 Training on Agility of Badminton Players Ages 12-15 Years
}

\author{
Taufiq Rahman, Syamsul Arifin, Herita Warni \\ Department of Sport Education and Health \\ Lambung Mangkurat University \\ Banjarmasin, Indonesia \\ taufiqrahmanulm@gmail.com
}

\begin{abstract}
This study aims to determine the effect of 'shadow eight training" on agility of PB badminton players ages 12-15 years. The research method used was a pre-experiment design method. The sample in this study were 10 badminton players who were at 12-15 years old taken from Mustika training centre Indonesia. The results showed that the pretest on agility of badminton players obtained an average $=7.1850$ seconds with a standard deviation $=\mathbf{0 . 5 0 4 2 3}$. The posttest of agility data resulted an average $=\mathbf{6 . 7 5 0 0}$ seconds with a standard deviation $=0.44850$. T-test results provided $t$-count $=8,184>t$-table $(9$; $0,025)=2,262$, with Sig. (2-tailed) = 0,000; it turned out that Sig. (2-tailed) $<0.05$; thus, the $t$-count is significant. The conclusion is there is an effect of "shadow 8 training" on agility of badminton players ages 12-15 years.
\end{abstract}

Keywords: exercise, shadow 8 , agility, badminton

\section{INTRODUCTION}

National development is the development of Indonesian people as a whole which is entirely based on Pancasila and the 1945 laws. The success of national development is greatly influenced by the quality of human resources, both as objects and as subjects. Sports coaching considered as an effort to improve the quality of human resources is directed at improving the physical, mental, and spiritual health conditions of Indonesian people to shape character and personality, discipline and sportsmanship as well as to achieve the highest achievements in order to improve the image of the Indonesian nation.

Likewise, in the era of globalization, which the development of Indonesian human resources will be directed to do more efforts to improve quality to actualize Indonesian people as a whole, the orientation of national development in the field of sports must be aimed at improving the quality of its human resources. In order to achieve the improvement of the quality of Indonesia's human resources, the movement to promote sports and sports community needs to be continuously improved so that the goals are optimally achieved.

Sports coaching, as early as possible, needs to be continued and carried out by utilizing science and technology that specializes in advancing sports achievements. Sports achievements are one of the indications of scientific and technological progress. Sports activities are not just for being healthy or for recreation. The function of sports, more than that, has changed and has a very important role, whether it is for individuals, groups, nations even between nations. This development has been emanated from various sports activities since twenty-five years ago. High achievement in sports is the prestige of the bearer of that achievement, no matter whether it is a person or a group. Even the victory obtained by a nation can directly reflect the level of progress of the nation.

In accordance with the description above, badminton is a sport that is very popular in Indonesia that many people play a role in optimizing the sport. The Badminton Association of Indonesia (PBSI), the badminton organization in the country, carries out large and very complex coaching. Public demands for badminton achievement have significantly increased the burden of the coaching effort.

PBSI, which was officially established on 5 May 1951 in Bandung, has experienced ups and downs of achievements. At All England in 1959, Indonesia sent several badminton athletes, who had won the Thomas Cup a year earlier. Indonesia's badminton achievements were satisfying. Two Indonesian badminton players, namely Ferry Sonneville and Tan Joe Hok appeared in the men's singles final round. Likewise, Susi Susanti and Alan Budi Kusuma won two gold medals at the 1992 Barcelona Olympics. We also need to remember that the sport of badminton walked in for the first time competed at the Olympics, even in world championships as in Thomas and Uber Cup winning the trophy several times.

However, the badminton performance in recent years has declined which is marked by the failure of the Indonesian badminton team at world events. It gives bad effects on the coaches and badminton coaches since they are considered unable to foster the achievements of the ambassadors of the nations competing at the event. In coaching sports achievements, there are five determinants that must be developed simultaneously; these factors are (1) athlete's personality (2) physical condition (3) technical skills (4) tactical skills (5) mental abilities [1].

The athlete's personality is a positive attitude carrying out the exercise duties, loyalty to the leader, humility, and a spirit of competition and achievement. On the other hand, physical condition is the process of developing the ability of physical activity that is carried out systematically and progressively to maintain or to increase the degree of physical fitness in order to achieve optimal physical workability. The ultimate goal is to increase the athlete's functional potential and develop bio motor abilities to the highest degree. 
The technique in sports is an important skill that must be possessed by an athlete before becoming skilled or professional. Therefore, the technique is really needed by an athlete. Technical skill in this context is a description of the ability or skill to perform the movements of a sport from basic movements to complex and difficult movements, including the deceptive movements that characterize the sport. Hence, technical skills are the results of the defense process.

\section{METHOD}

The method used in this study was the Pre-Experimental Design method. The purpose of pre-experimental design is to obtain information that is an estimate for information that can be obtained by actual experiments in circumstances that do not allow to control and manipulate all the relevant variables. The samples in this study were 10 badminton players ages $12-15$ years taken from Mustika training centre Indonesia. The design in this study used The One Group Pretest - Posttest design, which means that a group of subjects is subject to treatment for a certain period of time, while measurements are taken before and after treatment is given and the treatment effect qas measured from the difference between the initial measurement $(\mathrm{O} 1)$ and final measurement $(\mathrm{O} 2)$ [2].

\section{RESULTS AND DISCUSSION}

This research proves that shadow 8 exercises can increase the agility of badminton players significantly $(\mathrm{p}<0.05)$. This is proved by $\mathrm{t}$-count $=8,184>\mathrm{t}$-table $(9 ; 0,025)=2,262$, or with Sig. $(2$-tailed $)=0,000$; it turns out that Sig. $(2$-tailed $)=$ $0,000<\alpha=0.05$ thus, the t-count is significant, and the hypothesis proposed in this study is proven true. From the results of this study, it indicates that shadow 8 exercises can improve agility which are needed in badminton games. Agility is the ability to change the direction or position of the body quickly and is done together with other movement, so that athletes who have high agility make it possible to move quickly and easily in all directions [3]. To obtain high agility, shadow eight exercises really help to improve agile and regular foot movements to make players feel comfortable playing badminton. The ability to move to change direction and position depends on the situation and conditions encountered in a relatively short and fast time. Shadow step is the movement of footsteps that regulate the body to get the position of the body in order to facilitate the player in hitting the shuttlecock in his or her position [4].

To make benefits in training agility performance, athletes must apply dynamic strength when trained on the field. Lower intensity will not give any benefit. Thus, a slight positive is transferred to performance in athletes. To find out the ideal intensity to use in training, coaches must regularly test athletes to determine their maximum capacity to carry out a given exercise, intensity, and duration of agility training at a young age [5]. For agility and speed training, they must be done with high intensity at $80-95$ percent of the best performance athletes. The neuromuscular system on the quality of agility training depends on the nerve response and reactivity of the neuromuscular system; the agility of this type of training is often referred to as neuromuscular exercise. The ability of the central nervous system to send fast, strong and high impulses into the muscle fibers is involved in conducting agility exercises (ie, the level of muscle contraction).
Therefore, the intensity in training is very influential in increasing agility.

In order to get the greatest efficiency and benefit from agility training, coaches must arrange agility training and training tempo based on the dominant energy system used in certain sports. The duration of agility training is as follows: 1) Alactic anaerobic system. The duration of 5-10 seconds with very high intensity (> 90 percent) of the application of force and speed of action; the resting interval from 1 to 2 minutes. 2) Lactic acid anaerobic system [5]. Duration of 20 to 90 seconds with high intensity (80-90 percent); rest interval of 2 to 3 minutes.

To avoid the potentially detrimental effects of fatigue on high agility training performance, the total time of the training session must be between 5 and 10 minutes. When considered a rest interval (often lasting 2-3 minutes), the total agility training time per session can be as high as 35 minutes. For example, if during an agility training session the number of repetitions of the alactic system and lactic acid exercises 10 exercises for 10 seconds, 5 exercises for 15 seconds, and 5 exercises for 30 seconds ( 5 minutes and 25 seconds in total), then the number of rest intervals will be around 27 minutes (1 minute for a 10 -second exercise, 1.5 minutes for a 15 second exercise, and 2 minutes for a 30 -second exercise). It is the coach's responsibility to monitor the athlete in his development properly.

At the time of the exercise in the field, the researchers gave treatment by conducting initial tests in advance with a maximum test to determine the individual training load. In the exercise of the athlete's pulse, training is always calculated to find out the achievement of the $80 \%$ training dose. Researchers gave shadow 8 treatment for 6 weeks with a frequency of exercise 3 times a week. The volume of anatomical adaptation sessions should fall between 16 and 32 total sets, a hypertrophy session between 16 and 24 (and less than one hour in duration), a maximum strength session between 16 and 24, a power distribution between 10 and 16 , and a power endurance or short nuclear endurance session between 4 and 12 [6].

It can be concluded that in doing an exercise to be able to change physical conditions, in this case, agility required a large number of exercises between 16 and 24 meetings. In this study, the researcher conducted 18 meetings ( 6 weeks) in the treatment of exercises to improve agility using shadow 8 exercises of badminton players. The initial test reached an average of 7.18 seconds, and at the end of the test, an average of 6.75 seconds. It means that there was an increase in agility of badminton players of 12-15 years old by using shadow eight exercises. This is a result of providing treatment with exercises that lead to the progress of badminton players in increasing the agility provided by researchers.

Thus, the results of research conducted by researcher using shadow 8 exercises give a positive influence toward the improvement of agility. Shadow 8 training can be used as a form of agility training but with the correct training principles so that there are no mistakes in training, injury, or overtraining that endanger the players or athletes themselves. 


\section{REFERENCES}

Based on the data analysis, hypothesis testing, and discussion of the results, it can be concluded that there is an influence of shadow 8 exercises on agility of badminton players.

\section{ACKNOWLEDGMENT}

We would like to be thankful to the Dean of Teacher Training and Education Faculty, Lambung Mangkurat University, who has supported us and provided the funding. Therefore, we could join this International Conference.

[1] T. James. Kepelatihan Olahraga. Jakarta: Cerdas Jaya, 2012, pp. 63.

[2] Sugiyono. Metodelogi Penelitian Kombinasi. Bandung: Alfabeta PT Rineka Cipta, 2011, pp. 11.

[3] Widiastuti. Tes dan Pengukuran Olahraga. Jakarta: Rineka cipta, 2015, pp. 125.

[4] H. Subarjah. Permainan Bulutangkis. Bandung: CV. Nurani, 2007, pp. 32.

[5] T. Bompa and M. Carrera. Conditioning Young Athletes. United States: Human Kinetics, 2015, pp. 116-117.

[6] T. Bompa. Periodization: Theory and Methodology of Training. United States: Human Kinetics, 2015, pp. 127. 